\title{
EL REGALO PREVENIDO: NORMA Y PERSUASIÓN EN LA VIDA COTIDIANA DE LA EDAD MODERNA*
}

\author{
Mariela Fargas PeÑarrocha \\ Universidad de Barcelona
}

Fecha de recepción: enero 2012

Fecha de aceptación: febrero 2012

\section{UNA APROXIMACIÓN A LAS DIFERENTES PRÁCTICAS Y ACEPCIONES DEL REGALO}

El regalo es «mucho más eficaz que las palabras para persuadir» ${ }^{1}$. De ahí su atractivo, fuente de inspiración para antropólogos y más tarde historiadores ${ }^{2}$. De los muchos trabajos realizados por éstos, hoy ya podemos inferir unas cuantas cuestiones con las que iniciamos el trabajo que ahora se presenta ${ }^{3}$.

En un mundo de intensa vivencia de la religiosidad como la era moderna, el regalo va unido a numerosas advocaciones y cultos, como agradecimiento por los favores recibidos, como solicitud de intercesión ${ }^{4}$. El regalo fue auspiciado por la religión cristiana, expresión de piedad y caridad, si bien se ha dicho que perpetuaba las diferencias en tanto que oponía dádiva a salario. Estampas de santos, imágenes, crucifijos, se empleaban con estos fines ${ }^{5}$. Junto a ello, el papel de la familia, los amigos y clientelas, fueron también campo idóneo para la circulación de regalos, haciendo gala de las

* Realizado en el marco del Proyecto HAR2011-26435-C03-02 del MICINN.

1. ROBLEDO, L.: «El cuerpo como discurso: retórica, predicación y comunicación no verbal en Caramuel», Criticón, 84-85, 2002, p. 151.

2. ZIONKOWSKI, L. Y KLEKAR, C. (eds.): The Culture of the Gift in Eighteenth-Century England, New York, 2009.

3. DAVIES, W. y Fouracre, P. (eds.): The languages of gift in early Middle Ages, Cambridge-NY, 2010.

4. PeÑafiel, A.: «Cultos, advocaciones, donaciones y ofrendas en la Murcia del setecientos» en Rivas CARMONA, J. (coord..): Estudios de platería, Murcia, 2006, p. 450.

5. Bel BRavo, M.A.: Mujeres españolas en la historia moderna, Madrid, 2002, p. 133. 
«leyes de la amistad» que hiciera resurgir el humanismo ${ }^{6}$. En los círculos privilegiados, semejantes prácticas se dieron con mayor asiduidad, atento su educación en torno a una generosidad que debía mostrarse con ostentación. Lo avalaban los libros de cortesanía basándose en Aristóteles. Pero a medida que se asentó la Europa de las cortes, el regalo acabaría convirtiéndose en una estrategia de competitividad ${ }^{7}$. Algo más tarde, bajo la civilidad barroca, la apariencia permitía obtener aprobación. En ésa encrucijada adquieren todo su sentido el gasto excesivo y el regalo ${ }^{8}$.

Una cadena de prácticas del regalo iba a unir a los poderosos. No participar de ella significaba coartar las posibilidades de ascenso. Esta cadena permitía aunar procedencias, pues los artefactos que se hacían circular ponían en contacto grupos distintos con aspiraciones comunes. La cadena de intercambios permitía a unos disfrutar de objetos que en distinto tiempo habían pertenecido a otros. Los aspirantes a ennoblecerse podían ver compensados algunos favores con objetos de lujo que antaño hubieran decorado los envidiados hogares de viejos nobles. Pero es difícil desgajar esta cadena de otras prácticas económicas a las que se debían recurrir en época de dificultades. Una compraventa del siglo XV muestra a Juan de Moncada, residente en Sicilia, vendiendo al señor Ramon de Torrelles, de Barcelona, una fíbula de oro y piedras preciosas por tres mil florines de oro que tiempo atrás había lucido la reina Blanca de Sicilia como regalo de bodas 9 .

Los manuales de supervivencia política destacaron el significado del regalo como instrumento de seducción en las relaciones diplomáticas ${ }^{10}$. Oliván nos recuerda los guantes perfumados ofrecidos a los delegados extranjeros ${ }^{11}$. En su Conservación de monarquías, de 1648, F. Enríquez argumentaba cómo la conquista con las armas valía muy poco si, a base de «alagos, caricias, regalos...» no se ganaban las voluntades ${ }^{12}$. En relación a los espacios de poder de la Francia del XVII, Kettering analizó el regalo como potenciación de las redes clientelares: no existía, en principio, una obligación de corresponder, y la reciprocidad entre patrón y cliente se disfrazaba con la retórica de la cortesía. El intercambio de halagos entre los nobles, regulados, ocultó la reciprocidad obligatoria de la relación patrón-cliente creando un clima de confianza y generosidad.

6. BURKe, P.: El Renacimiento europeo, Barcelona, 2000, p. 169. Véase CRUZ, J.:»Del cortesano al hombre fino, una evolución de los ideales de conducta masculina en España desde el Renacimiento», Bulletin of Spanish Studies, 2, 2009.

7. García SAnto-Tomás, E. (ed.): Materia crítica. Formas de ocio y de consumo en la cultura áurea, Madrid, 2009, p. 176.

8. CANAVESE, G.F.: «Ética y estética de la civilidad barroca. Coacción exterior y gobierno de la imagen en la primera modernidad hispánica», Cuadernos de Historia de España, 78-1, 2003.

9. ANC, Sección Nobleza, MONCADA CP.305,D.12.

10. Colomer, J.L.: Arte y diplomacia de la monarquia hispánica del siglo XVII, Madrid, 2003, p. 20.

11. OlivÁn SAntaliestra, L. y Pilo, R.: «Recetario en busca de dueño: perfumería, medicina y confitería en la Casa del VII duque de Montalto (1635-1666)», Cuadernos de Historia Moderna, 37, 2012, en prensa.

12. Fernandez Albadalejo, P.: La crisis de la Monarquía, en Historia de España (eds. Fontana y VILLARES), vól. 4, Madrid, 2009, p. 341. 
Con el tiempo, este vínculo personal podría desarrollarse como vínculo emocional. Pero la entrega de regalos, la ficción amable, se metamorfoseó en un otorgamiento de beneficios, $y$, su inicial falta de interés por parte del donante, se convirtió al fin en obligación para el donatario. Si esta regla fallaba, la relación se disipaba o estallaba el conflicto ${ }^{13}$. La frecuencia del intercambio de regalos en el mundo cortesano es pues continua. Pero es que el uso de éstos tenía incluso una dimensión más elemental: el ser aceptado por el grupo.

Ni qué decir tiene la existencia del regalo como soborno. Los procesos de visita puestos en marcha para supervisar la actuación de oficiales registran numerosas indicaciones. Conocemos algunos de los sometidos a los miembros del entorno virreinal de Cataluña. Los expedientes de la visita de 1635 recogían la declaración del noble Francesc Junyent quién afirmaba «es público y notorio que la mujer del regente Sala toma muchas cosas que le dan y presentan para negociaciones que hace con los jueces de la Audiencia en causas civiles como criminales con sabiduría de su marido» ${ }^{14}$. Las prohibiciones dictadas por Juana de Castilla en 1515 dirigidas «a los alcaldes de las cárceles para el buen uso de sus oficios» nos describen en qué consistían los susodichos regalos: «...no sean osados de tomar dádivas de dineros, ni presentes, ni joyas, $n i$ viandas...» ${ }^{15}$. A éste respecto la cédula publicada, en 1788, por Carlos III mencionaría «La recta administración de justicia es inseparable de la integridad y limpieza de los Jueces por cuyo motivo les está prohibido tan seria y repetidamente en las leyes el recibir dones ni regalos de qualquiera naturaleza que sean de los que tuvieren pleyto ante ellos» ${ }^{16}$.

Otras dimensiones del regalo convivieron con las expuestas. Multitud de regalos eran reunidos a raíz de viajes y luego podían comercializarse bajo la etiqueta de objetos $\operatorname{curiosos}^{17}$. Las reliquias eran concebidas como regalos y como mercancías ${ }^{18}$. Los regalos también se entregaban por cortesía, amor, mantenimiento de la presencia simbólica para los que se encontraban lejos de su familia o de sus amistades ${ }^{19}$. Ahí cabe incluir la correspondencia ${ }^{20}$. S. Martínez recoge los reclamos de nuevas que Juan de Zúñiga expresaba a su amigo Juan de Silva desde Roma, donde ejercía como embajador de Felipe II ante el Papa Pío V, con la esperanza así de aliviar su soledad diplomática pues

13. Kettering, S.: «Gift-Giving And Patronage In Early Modern France», French History 2-2, 1987, págs. 131-151.

14. Archivo de la Corona de Aragón, Regia Visita, 49, fol. 26r.

15. Novísima..., Libro XII, Tít. 38, p. 482.

16. Novísima Recopilación, Libro XI, Tít. I, p. 172.

17. LóPEZ PÉREZ, M.: «Anatomía del virtuoso, coleccionismo y melancolía en la figura de V.J. de Lastanosa», Argensola. Revista de Ciencias Sociales, 115, 2005, p. 149.

18. CAstillo, J.: «Funciones sociales del consumo», Reis, 67, 1994, p. 65-85.

19. GARÍ, B., (coord.): Vidas de mujeres del Renacimiento, Barcelona, 2007, p. 89.

20. TRueBA, J.: El arte epistolar en el renacimiento español, Madrid, 1996, págs. 40, 54. MARTín BAÑos, P.: «Familiar, retórica, cortesana: disfraces de la carta en los tratados epistolares renacentistas» Cuadernos de Historia Moderna, IV, 2005, págs. 15-30. 
«no ay otro regalo para las pesadumbres desta corte si no las cartas de los amigos» ${ }^{21}$. Es pertinente recordar, como hace Trueba Lawand, que en la versión latina del De elocutione de Demetrio, que circuló en el siglo XIV, se define explícitamente la carta como el regalo enviado ${ }^{22}$.

Pero no acaba ahí la lista de posibles usos del regalo. También éste aparecía como fuente de información, como noticia. Los manuscritos estudiados por F. Bouza que corrían de mano en mano rescribiendo y reinscribiendo las últimas novedades que interesaban y emergían del entorno cortesano se sitúan ahí ${ }^{23}$. Nos relata Benedetta Craveri que la marquesa de Sevigné, que hacía acopio de historias sobre la corte del XVII, sus intrigas y esplendores, chismes, todo hilvanado en forma de carta se lo enviaba semanalmente a su hija como regalo ${ }^{24}$.

También el regalo estaba destinado a la supervivencia. Erasmo, con el fin de sufragar su vida de estudiante, no dudaba en buscar pensiones y regalos varios ${ }^{25}$. Parece que a él le gustaba realizar regalos que entrañasen un mensaje intelectual, por ejemplo, piezas materiales alusivas a discursos de grandes pensadores. En su carta de 1523 a John More, único hijo varón de Thomas More, decía así: «Mi querido John, como no me gustaría que pensaras que soy desagradecido a tus muchos regalos y amables cartas, te envío ahora ; todo un nogal;no rechaces este pequeño regalo, es muy elegante y muy de Ovidio... $\nu^{26}$. Con la finalidad de ayudar al sostenimiento de un nuevo hogar, en Inglaterra, los amigos y parientes ayudaban a los novios con regalos y colectas de dinero $^{27}$. El regalo y el reparto de alimentos, cuyo ancestral origen se remonta a la época de los cazadores-recolectores, forma parte de la hospitalidad ${ }^{28}$. Para Berking ello sugiere la división del sacrificio, el reconocimiento de la solvencia de los miembros de un grupo. Pero también, y al margen de los preceptos cristianos, la conservación del orden natural, las reflexiones clásicas de la gratitud y el respeto sociales ${ }^{29}$.

De la importancia de los regalos en el seno de las redes obligacionales, queda constancia en algunos libros de cuentas ${ }^{30}$. Sin embargo las de las cocinas aristocráticas

21. MartineZ, S.: «Significación Y Trascendencia Del Genero Epistolar En La Política Cortesana: La Correspondencia Inédita Entre La Infanta Isabel Clara Eugenia Y El Marqués De Velada», Hispania, LXIV/2, 217, 2004.

22. Trueba Lawand, J.: El arte epistolar en el Renacimiento español, Madrid, 1996, p. 22.

23. BouZA, F.: Corre manuscrito. Una historia cultural del Siglo de Oro, Madrid, 2002, p. 74.

24. CRAVETTI, N.: La cultura de la conversación, Madrid, 2007 (2ª ed.), p. 250.

25. Boorstin, D.J.: Los pensadores, Barcelona, 1997, p. 117.

26. SiLvA, A. de: Un hombre para todas las horas. La correspondencia de Tomás Moro, Madrid, 1998, p. 219.

27. SARTI, R.: Vida en familia, Barcelona, 2003, p. 93.

28. HEAL, F.: «Food gifts, the household and the politics of exchange in early modern England», Past and Present, 199, 2008, pp. 41-70.

29. BERKING, H.: Sociology of giving, Nothingam, 1999.

30. Krausman Ben-Amos, I.: The Culture of Giving: Informal Support and Gift-Exchange in Early Modern, Cambridge, 2008. 
no solían separar la mención de compras de la de los regalos. De la misma manera que era difícil distinguir entre los pagos a cuenta, de la obligación de vasallos, o los regalos entregados para distraer aquella ${ }^{31}$. Aún durante largo tiempo, persistiría la costumbre de servir a los señores con especiales prestaciones cuando éstos visitaban sus feudos, o de regalarles un animal en ocasión del casamiento de las hijas ${ }^{32}$. La contabilidad de las grandes casas revelaba así mismo los innumerables regalos entregados a los criados en ocasión de celebraciones familiares, prueba una vez más de su política paternalista. A consecuencia de semejante dispendio, Sebastián Casanovas, narra con profundo lamento -como anota James Casey- el resentimiento albergado contra su abuela paterna por haber despilfarrado su dote en hacer excesivos regalos, para al fin verse abocado ante un patrimonio cargado de insostenibles deudas ${ }^{33}$. Y es que el vivir noblemente implicaba, como sugería la condesa de Aranda en el siglo XVII, cuyos avisos recoge Atienza: «Defended vuestros vasallos siempre (...) dándoles favores y fuerzas (...) Mostrad gusto de que busquen y se les de a todos los vasallos (...) con liberalidad en vuestra casa los regalos, y cosas extraordinarias, que no puede aver en las suyas cuando la necesidad les obliga a pedirlo» ${ }^{34}$. Hay constancia de la numerosa documentación, entre libros y papeles sueltos, que el duque de Osuna ordenó elaborar por los regalos de animales, vacas, cabras, hechos a sus vasallos de los lugares de Béjar a principios del XVIII ${ }^{35}$.

Ben Amos ha destacado la función solidaria del regalo, en donde la familia y la parentela ejercen un protagonismo de primera línea, seguido por el que desarrollan gremios, parroquias y hospitales. Todo este conjunto teje un tipo de sociabilidades contra la que no se opondrá la renaciente economía de mercado, antes al contrario se producirá una pacífica convivencia entre ambos modos de intercambio ${ }^{36}$. Precisamente esta dimensión ha sido la que más ha llamado la atención por parte de la antropología, a partir de los clásicos estudios de Godelier y Mauss. El ensayo de éste último trató la manera en que el intercambio de objetos entre los grupos articulaba y construía las relaciones. La serie resultante establecía una de las primeras formas de economía social y solidaridad. La llamada economía del don, siguiendo ahora a L. Hyde, erigió el regalo a la categoría de substrato teórico para la comprensión de una comunidad en la que las relaciones económicas funcionarían mediante la entrega de bienes y servicios sin previo acuerdo de correspondencia. Pero el regalo es un bien móvil, y ésta es la

31. HEAL, F.: «Food gifts, the household», pp. 41-70.

32. CASEY, J. ARDIT, M.: España en la edad moderna. Una historia social, Valencia, 2001, p. 156.

33. CASEY, J.: España en la Edad moderna, p. 301.

34. ATIENZA, I.: «El señor avisado: programas paternalistas y control social en la Castilla del siglo XVII», Manuscrits, 9, 1991, págs. 155-204.

35. ANC, Nobleza, ES.45168.SNAHN/1.42.9.1//OSUNA,C.259,D.8-9.

36. ToHEN, I.: Strategic affection? Gift Exchange in seventeenth Century Holland, Amsterdam, 2007, págs. 45-97. 
condición para que el sistema siga funcionando ${ }^{37}$. Godelier, como el anterior, actualizó la tesis de Mauss, ubicando los objetos y los actos como mediadores de sistemas de intercambio que no se agotan en el beneficio económico, sino que explican nociones como autoridad, sumisión, o violencia ${ }^{38}$. En los últimos años se han realizado esfuerzos interdisciplinares que han cuestionado la reciprocidad maussiana y han incorporado nociones como género (A.E. Komter), multiplicidad de capitales (P. Bourdieu), o la imposibilidad del don (J. Derrida) ${ }^{39}$. Desde semejante complejidad, la etnografía del regalo que Zemon Davis dibuja para la Francia del siglo XVI, recoge el interrogante clásico sobre la relación entre la economía del don y la economía de mercado: para la mentalidad de la época era imposible escindir contrato de amistad, de manera que salarios y dádivas se acompañaron pacíficamente ${ }^{40}$.

Y no es posible obviar las aportaciones realizadas a partir de la historia del arte: con el regalo muchas casas nobles fueron ampliando sus colecciones, como recuerda Noelia García en un trabajo sobre Mencía de Mendoza: desde los obsequios de ámbito familiar, joyas de gran valor; hasta los presentes con vocación diplomática, en ocasión de las estancias; pasando, finalmente, por los regalos fruto de visitas, de la participación en fiestas nupciales. En estos casos se trata de objetos de gran lujo, arte y paramento del hogar de singular calidad ${ }^{41}$.

Entre damas y princesas también se enviaban alimentos como regalo, especialmente conservas dulces. Los códices del gusto, eran signo de refinamiento y vuelven a converger en el regalo ${ }^{42}$. Siguiendo la tradición navideña el turrón jugaba un papel importante como obsequio. El dietario del barón de Maldá no olvida describirlo. Lo mismo nos dice en relación a los dulces regalados a las personas que se visitaban para presenciar juntos las procesiones del Corpus o Semana Santa ${ }^{43}$. Los panellets, tenían un especial carácter simbólico y los jóvenes los regalaban a las doncellas a quienes deseaban cortejar ${ }^{44}$. No hay que olvidar que el regalo admitía otra noción relacionada

37. HYDE, L: The Gift: Imagination and the Erotic Life of Property, en especial el primer capítulo, «A Theory of Gifts», London, 1982.

38. Presta, S.: «La categoría de don en el marco de la economía social y solidaria», Cuadernos de Antropología Social, 26, 2007. Godelier, M.: «De las cosas que se dan, de cosas que se venden y de cosas que no hay que dar ni vender, sino guardar», El enigma del don, Barcelona, 1998.

39. Komter, A.E.: The gift, an interdisciplinary perspective, Amsterdam, 1996. Del mismo autor, Social solidarity and the gift, Cambridge, 2005. OsTEEN, M. (ed.): The question of the gift, essay across disciplines, London, 2002. GouX, JJ et alii.: The enigma of gift and sacrifice, Washington, 2002.

40. Zemon DaVis, N.: The Gift in Sixteenth-Century France, Madison, 2000.

41. GARCía PÉREZ, N.: «Mencía de Mendoza y el intercambio de regalos : una práctica obligada entre las élites de poder», en RIVAS CARMONA, J. (coord..), Estudios de platería, Murcia, 2006, pp. 157 y ss.

42. PÉREZ SAMPER, M.A.: « Los recetarios de mujeres y para mujeres. Sobre la conservación y transmisión de los saberes domésticos en la época moderna», Cuadernos de Historia Moderna, 19, 1997, págs. 121154.

43. ÍD,«Espacios y prácticas de sociabilidad en el siglo XVII. Tertulias, refrescos y cafés en Barcelona», Cuadernos de Historia Moderna, 2001, 26, p. 27.

44. ÍD, «Comer, beber y diverstirse», en Fiesta, juego y ocio en la Historia, Salamanca, 2003, págs. 173 y ss. 
con la buena alimentación, los placeres de la mesa ${ }^{45}$ y la salud, tal como se leería en $E l$ regalo de la vida humana de Juan Vallés, recetario médico del XVI ${ }^{46}$.

El ritual de los regalos ha tenido mucha relación con los códigos del amor. En algunas de las obras de Mariana de Carvajal, como Navidades de Madrid, de 1663, aparece el regalo entre galanteos: «El diligente día primero de Pascua, por ser doña Gertrudis la obligada, le pareció a don Vicente enviarle algunos regalos, y con la licencia de Pascua, como por aguinaldo, en una curiosa bandeja le envió búcaros dorados, guantes de ámbar, bolsos estrechos y otras niñerías. Estimó la demostración, y quiso darlo a entender, y poniendo cuatro lienzos de Cambray en la bandeja, le envió a decir que por ser labor de su mano se atrevía». La autora nos recuerda que una mujer no podía enviar regalos a un hombre a no ser que perteneciese a su familia, que se tratase de algo confeccionado por ella o que se enmarcase en una celebración religiosa. Un caballero tampoco podía tomarse la libertad de enviarle regalos a la dama cortejada, ni ésta podía darse el lujo de aceptarlos siempre ${ }^{47}$.

Los tiempos en los que la presencia de los regalos era más intensa son las fiestas nupciales y el calendario religioso ${ }^{48}$. Navidad, Año Nuevo y Pascua constituían ocasiones propicias para que damas y reinas repartiesen regalos a los más allegados de su corte ${ }^{49}$. En el estudio de la correspondencia intercambiada en ocasión de una noble boda alicantina del XVIII, Alberola y Die ofrecen toda suerte de detalles sobre la elección de los regalos ${ }^{50}$. En cuanto al ciclo de las bodas ${ }^{51}$, Klapish Zuber escribió que en el sistema dotal la inicial reciprocidad se tornaba igualdad en el momento en que, ya casados, los novios recuperaban los bienes entregados, práctica inscrita en el derecho de retención ${ }^{52}$. La entrega de regalos por parte del novio o de su familia a la novia, era parte de su derecho al honor, así como su compromiso con la alianza ${ }^{53}$. Viajando al vértice más elevado de la jerarquía, Checa ha señalado que el matrimonio entre Margarita de Austria y el príncipe don Juan en 1497, constituye uno de los pocos que para la época han conservado documentación pormenorizada acerca de los regalos entregados

45. QUELlier, F.: Gourmandise. Histoire d'un péché capital, Paris, 2010.

46. Juan Vallés. Regalo de la vida humana. Transcripción del manuscrito y coordinación: Fernando Serrano Larráyoz, Pamplona, 2008.

47. Cubillo Paniagua, R.: Usos amorosos y conductas modélicas femeninas en el siglo XVII: una lectura de las navidades de madrid y noches entretenidas de mariana de Carvajal, TD, UAB, 2003, pp. 198 y 206.

48. PURBRICK, L.: The wedding present, domestic life beyond consumption, London, 2007.

49. GASCÓN, I.: «La vida cotidiana de tres reinas de la Corona de Aragón a través de sus libros de cuentas», Pedralbes. Revista d'Història Moderna, 24, 2004, p. 39.

50. Alberola, A. y Die Maculet, R.: «Una Boda En La Pequeña Nobleza Alicantina Del Setecientos: Los Soler De Cornellá Y Los Juan A Través De Su Correspondencia», Revista De Historia Moderna 13/14, 1995, págs. 253-311.

51. El más representativo en el regalo, para LÉVI-STRAUSS, C.: Introduction to the Works of Marcel Mauss, London, 1987.

52. FAir BeStOR, J.: «Marriage Transactions in Renaissance Italy and Mauss's Essay on the Gift», Past \& Present, 164, 1999, pp. 6-46.

53. BRUCKer, G.: Giovanni y Lusanna. Amor y matrimonio en el Renacimiento, Madrid, 1991, p. 31. 
a la joven por sus suegros, como recoge el Libro de las Joyas: collares de oro, esmaltes y diamantes, perlas y sortijas, a los que siguen vestidos y terciopelos, plata y ropajes de carácter ornamental, tapicerías y alfombras, listado que finaliza con los libros, de horas, de tipo litúrgico, y también de damas ${ }^{54}$.

Los usos percibidos por el estudioso no fueron ajenos a los discursos propios de la edad moderna española. Baste recordar el texto del Tesoro de la lengua castellana de Covarrubias del año 1611, donde para esta voz, se sigue:

«Regalo. Trato real y regalarse tener las delicias que los reyes pueden tener a rege. Sin embargo desto me parece auerlo dicho del nombre Griego porque los antiguos tenian por suave y gustosa comida todo lo que se hacía de la leche y oy me parece pro piamente podemos llamar regalo la manteca del ganado y las demas cofas que se hazen de la leche. Regalado, el que se trata con curiosidad y con gusto especialmente en su comida. Regalon, el muchacho regalado de sus padres. Regalador, el amigo de agasajar a otros.... ${ }^{55}$.

Baste, finalmente, indicar las definiciones que reúne el Diccionario de la Lengua Española del año 1737:

«Dádiva que se hace o envia voluntariamente o por costumbre. Regalo Significa tambien gusto o complacencia que se recibe en qualquier. Regalo Se aplica assimismo a la comida y bebida delicada y exquisita. Regalo Vale assimismo conveniencia comodidad u descanso que se procura en orden à la persona. Regalo En el sentido mystico se llama la aflicción trabájo u penalidad con que mortifica y trabaja Dios a sus criaturas» ${ }^{56}$.

\section{EL REGALO REGULADO}

Si nos cuestionamos por el regalo en su dimensión política, encauzado al gobierno de sí mismo o de la familia, de la conducta que al individuo le pone en relación con los demás dirigida a un fin, sociabilidad, interés, y todo ello en el seno de lo cotidiano, nos encontramos ante un sistema de reglas morales y normas sociales.

Para hablar de ello hay que comenzar por las leyes suntuarias, que en su afán por regular la diferenciación social basada en el lujo para evitar la ruina de las familias y garantizar el ahorro que revertiría en la fiscalidad ${ }^{57}$, proponían límites en la entrega de regalos $^{58}$. Especial atención captaba el ciclo nupcial. Ya en las cortes de Alcalá de 1348 Alfonso XI limitaba el número de vestidos que el marido podía regalar a la mujer antes y después de la boda bajo pena de perder la tercera o la cuarta parte de sus bienes. En este punto los tratados morales insistieron una y otra vez, prueba de la escasa eficacia

54. CHECA, F.:«Fiestas, bodas y regalos de matrimonio. Del tesoro principesco al inicio del coleccionismo artístico en las cortes habsbúrgicas de la época de Juana de Castilla (1498-1554)», Juana I en Tordesillas, Valladolid, 2010, p. 138.

55. Covarrubias, S.: Tesoro de la lengua castellana, Madrid, 1611.

56. Diccionario de la lengua castellana del 1737, 6 edición, Madrid 1822, p. 702.

57. PÉrez Martín, A.: «El derecho y el vestido en el Antiguo Régimen», Anales de Derecho, 16, 1998, 261289. Jurado Sanchez, J.: «Lo superfluo, una cosa muy necesaria. El consumo suntuario en la literatura de la Ilustración», en L. PERDICES y M. SANTOS, (coord.), Economía y literatura, Madrid, pp. 195-228. 58. Sempere y GuARINOS, J.: Historia del luxo y de las leyes suntuarias de España, Madrid, 1788, p. 55. 
de éstas normas. En los años 1534 y 1573 la cuantía de las dotes castellanas también fue delimitada «atento el desorden y daños (...) que se han recrecido y recrecen de las dotes excesivas que se prometen». De nuevo por la pragmática de 1623 se insiste en lo mismo «porque el exceso y punto a que han llegado los gastos que se hacen en los casamientos (...) consumen las haziendas, empeñan las casas».

Junto a los gastos de bodas, el matrimonio como relación económica, y el regalo como donación entre esposos, constituyó uno de los capítulos más controvertidos de la legislación civil matrimonial. Desde la compilación justinianea, el derecho se encuentra orientado a prevenir posibles fraudes, además de buscar la proporcionalidad entre ambos cónyuges y eludir un enriquecimiento injusto. El ordenamiento recorría la tipología de bienes que se adquirían como donaciones entre esposos, las cantidades y valores permitidos, y sus efectos, especialmente ante la disolución del matrimonio. En Castilla las Partidas ya distinguían entre los regalos entregados para el enlace y aquellos que tenían lugar durante la vida conyugal. Los primeros eran las donaciones esponsalicias y arras. Las donaciones esponsalicias podían ser entregadas tanto por los esposos entre sí «en señal de afecto y cariño», en cuyo caso se consideraban auténticos regalos de boda, como por los padres y parientes. En éste último caso los bienes no serían reputados como donaciones esponsalicias propiamente dichas salvo si el regalo se realizase a uno de los esposos en consideración del otro. La legislación precisaba pues con meticulosidad la procedencia del regalo, y aún los registros notariales debían indagar acerca de la auténtica voluntad de los donantes, dado que al efecto individual se oponía el efecto de ganancial que hacía que los regalos se integrasen en la sociedad conyugal. La pragmática de 1623 , reiterada por la de 1713 , iba más allá y limitaba el valor de los regalos, pues los que el esposo hiciese a su esposa no podían exceder más allá de la octava parte de lo que la mujer había aportado por razón de dote. Sin embargo no se ponía límite alguno cuando era la mujer la que regalaba al marido. De lo anterior se derivaba que los contratos, pactos y promesas que se hicieren en fraude de esta disposición, resultarían nulos, como resultarían así mismo perdidas las alhajas, joyas, o vestidos que se diesen habiendo excedido el límite indicado. La norma perseguía garantizar el dominio de los bienes del donatario y su transmisión. En el mismo año de 1623, se ratificaba que las arras entregadas por el novio no debían superar la décima parte de los bienes libres. Como complemento a esta medida y siguiendo la misma política limitadora se prohibía que cualquier comerciante, platero, pudiera pedir en juicio el valor de las joyas que hubiesen vendido al fiado para bodas ${ }^{59}$.

Desde antes de las Partidas alfonsinas las leyes no olvidaban prever la devolución de los regalos en el caso de que el matrimonio no se llegase a celebrar. Se distinguían las causas. Las Partidas indicaban que no era lo mismo si se había dejado de celebrar por culpa del donatario, o bajo consentimiento de ambos. En el primer caso, los regalos debían devolverse al donante. También perdía los regalos el donante si éste se presentaba como el culpable. Y si la culpa residía en el donatario, los había de restituir dobla-

59. Novísima Recopilación, tomo V, Libro X, 1805, pp. 22, 23. 
dos. Cuando el matrimonio dejaba de celebrarse por una casualidad, la ley disponía que si no había mediado ósculo en la celebración de los esponsales, debía devolver la novia a los herederos del novio lo que recibió de este. Pero, si había mediado ósculo, tan sólo devolvería la mitad. Finalmente cuando por voluntad ó consentimiento de ambos no llegara a efectuarse el matrimonio, se cumplía lo pactado por escritura pública. La ley 54 de Toro reiteraba estos extremos para el caso de la disolución del matrimonio, distinguiendo de nuevo entre intervención del beso y consumación de aquél. En el primer caso la esposa se quedaba con la mitad de lo donado. En el segundo caso se disponía que si a la mujer se le hubiese prometido arras además de la donación esponsalicia, sólo tendría derecho, ella o sus herederos, a escoger una de las dos cosas.

Durante el matrimonio, toda donación efectuada de un cónyuge a otro era nula, a excepción de los regalos módicos en ocasiones de regocijo para la familia. Las Partidas declaraban nulas estas donaciones y anteriormente se establecieron ciertas prohibiciones por encima de determinadas sumas: «Durando el matrimonio facen á las vegadas donaciones a la muger o ella al marido, non por razon de casamiento, mas por amor que se han de so uno el otro con el otro. Et tales donaciones como estas son defendidas que las non fagan porque non se engañen despojandose el uno al otro por el amor que se han de so et porque el que fuese escaso serie de mejor condicion que el que es franco en dar. E por ende, si las hecieren, después que el matrimonio es acabado, non deven valer...». Tras las Partidas, serán las leyes de Toro las que contengan mayor número de preceptos relativos a esta materia, reiterando el contenido de aquellas. La mayor parte de los textos morales de la época recordaban que semejante prohibición también estaba reconocida por el derecho canónico «por quitar con esto la ocasión a que con el amor se despojasen el uno al otro. Si bien una ley del fuero dize que esta prohibición sen entienda el primer año, porque passado él, cessa el fervor del amor, con que cessa también la razón de la prohibición». Con estas palabras se dirigía Machado de Chaves a sus confesores ${ }^{60}$. El mismo Sanchez, autor de De Sancto Matrimonii Sacramento, incluye estas cuestiones: el libro sexto aborda la problemática sobre las donaciones entre cónyuges, los supuestos de validez e ineficacia ${ }^{61}$. La doctrina jurídica discutió harto al respecto, atendiendo al género de las joyas y vestidos donados durante la vida conyugal, -si eran ordinarios formaban parte de la obligación de alimentos-, a la verdadera intención del marido e incluso a su propia riqueza. Jamás se puso en duda el regalo moderado. Tomemos para ello las palabras de fray Antonio de Guevara en sus Epistolas Familiares: «A los principios de su casamiento debe el sagaz marido halagar, regalar y enamorar a su mujer $\rangle^{62}$. No es ocioso indicar aquí que hasta la definición del pan de boda que ofrecía el Diccionario de Autoridades decía así: «Pan de la boda. Se llaman los regalos, agassajos y buen tratamiento, que se suelen hacer los primeros

60. Perfecto confesor, Barcelona, 1641, p. 590.

61. Carrodeaguas, C.: La sacramentalidad del matrimonio, doctrina de Tomás Sanchez, S.J., Madrid, 2003.

62. GuevarA, A. de: Epístolas Familiares, Madrid, ed. 1618, p. 192. 
dias, especialmente por el marido a la muger, que despues faltan por lo regular ${ }^{63}$. En otros territorios, como Cataluña, prevalecía esta reprobación. El sistema dotal explica también el objeto de estas prohibiciones. La propiedad individual está por encima del posible enriquecimiento de uno a costa del empobrecimiento del otro. En territorio aragonés, marido y mujer podían donarse bienes excepto los incluidos en la dote y el aixovar, y los bienes de tipo muebles ${ }^{64}$.

El regalo o regalos entregados en ocasión de la promesa de matrimonio tuvo, finalmente, una dimensión probatoria que permitió a muchas mujeres abandonadas reclamar ante los tribunales los efectos de un compromiso secreto, o resarcir de algún modo la entrega de su honra ${ }^{65}$. Son numerosos los pleitos por promesas, atento la persistencia de la costumbre que aún entendía el verba de futuro como contrato. Veamos algunos ejemplos. Para los pleitos de la Zamora del XVI Pinar nota la relevancia de alusiones a las sortijas, entre este tipo de donas, algunas de las cuáles iban acompañadas de íntimas inscripciones, pero también la entrega de claveles, refrigerios, alimentos o envío de hierbas para la curación de la amada. Cada uno de estos actos presumían la existencia de un vínculo, mientras que la otra parte alegaba tratarse de la simple devolución de un favor determinado ${ }^{66}$. En la Cantabria del XVIII Mantecón narra la entrega por parte de un montañés a su prometida de una sortija con cinta, significando posesión y enlace. Cuando los regalos consistían en objetos religiosos, cruces y rosarios, parece que era mayor la voluntad de solemnizar algún día el matrimonio ante la Iglesia ${ }^{67}$. Durante el tiempo en que las leyes tridentinas y civiles sobre la celebración del matrimonio aún tendrían que esperar para penetrar holgadamente entre las mayorías, el regalo-prueba determinaría casi totalmente los efectos y el conocimiento público de las relaciones entre los jóvenes. Lo cotidiano, en fin, dimensionado a lo normativo; lo privado, coadyuvante de lo colectivo.

\section{CONTRA LA VIDA VIRTUOSA, LA VIDA REGALADA Y LA PERSUASIÓN INTENCIONADA}

Reflejo de un excesivo bien material, el regalo no era considerado algo propicio si a lo que se aspiraba era a una educación virtuosa. En las cartas de Estefanía de Requesens a su madre, esta dama deja constancia de semejante prevención en relación a su hijo pequeño: «Lloyset está molt bonico y més gros que mai l’haja vist, guart lo

63. Citado en PÉrez SAMPer, M.A.: «El Pan nuestro de cada día en la Barcelona moderna», Pedralbes. Revista d'Història Moderna, 2002, 22, p. 33.

64. LALINDE, J.: «Capitulaciones y donaciones matrimoniales en el derecho catalán», Revista Jurídica de Cataluña, 64, 1965, págs. 615-680.

65. CAndau Chacón, M. L.: «Entre lo permitido y lo ilícito: la vida afectiva en los Tiempos Modernos», Tiempos Modernos, 18, 2009-1.

66. LORENZO PINAR, F-J.: «Conflictividad social en torno a la formación del matrimonio», Stvdia Histórica, $13,1995,131-154$.

67. ManteCon, T.A.: Conflictividad y disciplinamiento social en la Cantabria rural del antiguo régimen, Santander, 1997, págs. 37-38. 
Déu, y continua son estudi per maravella y es molt ben criat, sense ningun regalo». No hay que descartar, con todo, el sentido del regalo como sinónimo de un bienestar necesario, en especial para aquellos que así lo necesitaban atento su frágil salud. La misma Estefanía en el verano de 1537 le recomienda a su madre que tome cuidados ante la realización de un viaje, siguiendo la instrucción de sus médicos: «Segons me diuen li es contraria la molta calor, y per a enpendre tan llarg cami me par que deu vostra senyoria prendre lo parer de mestre Amiguet y de aqueixos altres metges (...) fent les jornades chiques, y no caminant en la sesta sino matinades y vesprades y ab tot lo regalo que sia posible» ${ }^{68}$. Aún en el XVIII, cuando el lujo comenzaría a ser instrumentalizado con fines tributarios, el autor de Del espiritu de las leyes escribiría cómo «La juventud criada en tan viles y bajos sentimientos imbuida en la facilidad de tener un establecimiento solo piensa en el regalo, en las diversiones y frivolidad.... ${ }^{69}$. También el Discurso sobre la educación de Campomanes incluye alusiones al regalo como problema, disuasorio de la virtud y del trabajo. En el capítulo preliminar el autor comienza proponiendo al lector detenerse ante el relato de una contienda entre el trabajo y la ociosidad que él extrae directamente de otro escritor, Jenofonte. El protagonista del relato es Hércules, que se enfrenta ante la aventura de optar entre dos caminos opuestos. Dilatadas descripciones señalan el sentido de cada uno. Para el camino del vicio y el ocio, el conde utiliza, entre otras, estas expresiones: «... para comer con deleyte buscas exquisitos cocineros, y para beber de la misma manera tienen varios y preciosos vinos. En el estio de acá y de acullá andas buscando nieve: para dormir suavemente no sólo te contentas con cama blanda, sino también pones almohadas sobre almohadas, y un regalo sobre otro» ${ }^{70}$. Una larga tradición que parte de la ética nicomaquea para la que el estagirita afirma que «el vulgo y la gente común por la suma felicidad tienen el regalo» ${ }^{71}$, habla de ello en relación a los vicios que perturban la rectitud de las personas «pues el regalo es argumento de flaqueza» ${ }^{72}$.

Lejos pues de los seductores y refinados ambientes en donde los regalos se pasean orgullosos de la mano del éxito y la civilización, el regalo y el vicio estrechan sus fuerzas para los gustos más austeros. La pluma de la mística no duda en convertirlos en uno de sus temas preferidos. San Juan de la Cruz escribe: «Estos también tienen tedio cuando les mandan lo que no tiene gusto para ellos. Y porque se andan al regalo y sabor del espíritu son muy flojos para la fortaleza y trabajos de la perfección; hechos

68. Epistolaris d'Hipolita Rois de Liori i Estefanía de Requesens, AHumada, L, ed.: Valencia, 2003, pp. $100,307$.

69. MonTesquieu, barón de: Del espíritu de las leyes, vól. 1, Madrid, 1820, p. 302, traducción castellana de J. López de Peñalver.

70. CAmpomanes, conde de: Discurso sobre la educación popular de los artesanos y su fomento, Madrid, 1775, p. 49.

71. SimÓn ABRIL, P.: La ética de Aristóteles, Madrid, ed. de 2001.

72. GranADA, Fray Luis de: Memorial de la vida cristiana, Tratado VI, Biblioteca de Autores Españoles, tomo II, Madrid, 1848, p. 368. 
semejantes a los que se crían en regalo...» $\gg^{73}$. También son significativas las palabras de fray Luis de Granada: «porque los grandes amadores de si mesmos son muy regalados y amigos de pasatiempos y deleites». No en vano buena parte de la pedagogía de la época excluye de la educación el regalo: «que un padre virtuoso y discreto cría sin ningún regalo» ${ }^{74}$. Gaspar de Astete ampliaba el compromiso para reforzar este tipo de educación, no sólo a la familia, sino a los maestros, cuando afirmaba que el «Deber (...) también se extiende a los maestros, porque con el temor deprenden y se aprovechan, con el regalo se descuidan y se pierden.. $\gg^{75}$. Muchas décadas después, el trabajo sobre la educación de los niños de Locke contaba con un capítulo dedicado a las recompensas que los padres podían o no hacerles a los pequeños: «Es preciso evitar con el mayor escrúpulo hacer cariños a los niños dándoles las cosas que apetezcan bajo la idea de recompensa para empeñarles a cumplir con sus deberes. El que ofrece a su hijo confites, manzanas u otra cosa semejante, con el fin de obligarle a que estudie su lección, o a que ejecute lo que se le mande, no hace sino autorizarle el amor que tiene a los placeres (...) En vano esperan los padres poder vencer esta pasión en sus hijos si se empeñan por una parte en indemnizarlos del freno que les pongan, proponiéndoles por otra nuevos objetos capaces de satisfacerla. Para que un niño llegue un día a ser sabio, hombre de bien y virtuoso, es preciso enseñarle a que domine sus pasiones y reprima la inclinación que todos tienen a las riquezas, a las galas, y a la comida regalada ${ }^{76}$. A principios del siglo XVIII el franciscano Arbiol alertaba a»los padres descuidados (...) que sí crían á sus hijos con regalo» ${ }^{77}$. Los manuales para la enseñanza de las primeras letras seguían entonces cuestionando el uso del regalo como recompensa para alentar a los niños al trabajo, determinando como buenos los regalos espirituales, sonrisas y alabanzas, imágenes religiosas, o fruta ${ }^{78}$. La literatura de ficción tampoco descuidó estos aspectos. Calderón escribiría: «Un padre que a castigar llega a un hijo no por eso deja de tenerle amor; antes le muestra mayor cuanto con mayor exceso, le hiere de enojo lleno y hace del dolor regalo» ${ }^{79}$.

Pero no acaban ahí los efectos perniciosos del regalo. Para Antonio de Guevara, la vida regalada era contraria a la salud pues «Que a la salud ninguna cosa la conserua tanto como es el trabajo y ninguna cosa la destruye tanto como es el regalo» ${ }^{80}$, si bien en sus Epistolas Familiares aclara que las bondades del regalo se encuentran en fun-

73. Escritores del siglo XVI, Biblioteca de Autores Españoles (BAE), tomo I, Madrid, 1853, p. 107.

74. Memorial de la vida cristiana, BAE 122, pp. 271, 388.

75. Morgado GARCíA, A.: «Teología moral y pensamiento educativo en la España moderna», Revista de Historia Moderna. Anales de la Universidad de Alicante, 22, 2002, p. 25.

76. LOCKE, J., Educación de los niños, tomo I, Madrid, 1797, p. 112.

77. Arbiol, fray A.: La Familia Regulada con doctrina de las Sagradas Escrituras, Madrid, 1789, Pag 192.

78. IMPARATOR PRIEUR, S.: «La enseñanza de las primeras letras en España en la segunda mitad del siglo XVIII», Contextos educativos. Revista de educación, 3, 2000.

79. Comedias de Calderón, BAE, Madrid, 1862, p. 366.

80. GuevarA, A. de: Aviso de privados y doctrina de cortesanos, Barcelona, 1612, p. 195. 
ción de su tipo y cuantía: «Para estar hombre más sano y vivir menos enfermo, bien tengo creido que aprovecha al hombre el buen regimiento y algun mediano regalo» ${ }^{81}$.

No es de extrañar pues que el esplendor del mundo cortesano se convirtiese en blanco de ataques: para el Quijote «... el buen paso, el regalo y el reposo, allá se inventó para los blandos cortesanos, mas el trabajo, la inquietud y las armas, solo se inventaron é hicieron para aquellos que el mundo llama caballeros andantes (...) pero triunfan ahora por pecados de las gentes la pereza, la ociosidad, la gula y el regalo...» ${ }^{82}$. El rechazo a estas prácticas cortesanas no sólo era provocado por su mal ejemplo, pues como escribiría Saavedra Fajardo «cuando, descuidados los ciudadanos, se entregan al regalo y delicias, sin poner las manos en el trabajo, son enemigos de sí mismos» ${ }^{83}$, sino que, como ha estudiado una parte de la historiografía acerca del poder, se erigía en serios avisos de regeneración política ${ }^{84}$. Para Quevedo «Detrás destos dos venia el diablo del cohecho y este diablo tenia linda cara y talle cofa que no vi en otro y era como un oro y me parece que le he visto en mil diferentes partes, en unas revocado, en otras descubierto, llamándose unas veces niñería, otras regalo, otras presente, otras limosna, otras paga, otras restitución, y nunca le vi con fu nombre proprio.... ${ }^{85}$. La dualidad «espíritus amigos del regalo y enemigos del trabajo» devendría pues una constante entre la literatura moral y política ${ }^{86}$. De igual modo Juan de Santa María, en su Tratado de república y policía cristiana, escribía «... ni hará hechos famosos y de nombre quien teme el trabajo y se da todo al regalo....» ${ }^{87}$. Por sus nefastas consecuencias, para el mismo Juan de Mariana la vida regalada era causa de degeneración en las dinastías reinantes: "Dudóse adelante si seria mas á propósito y mas cumplidero á los pueblos, muerto el príncipe, que eligieron dalle por sucesores á sus hijos y deudos, ó tornar de nuevo á escoger de toda la muchedumbre el que debía mandar. Recelábanse que el poder del rey que ellos dieron para bien común con la continuación del mando y seguridad de la sucesión de hijos á padres no se convirtiese en tiranía, sabía muy bien que á las veces los hijos por los deleites de que hay gran copia en las casas reales y por el demasiado regalo se truecan y no salen semejables á sus antepasados» ${ }^{88}$.

Teniendo en mente el regalo virtuoso, la solución, en definitiva, a fin de cumplir con prudencia con las cortesías propias de la educación de cada estado y estamento, parecía pasar por ofrecer regalos espirituales, sin duda los de mayor goce: «no ay regalo, como el divino Sacramento», exclamaba Gracián ${ }^{89}$. El regalo de la oración

81. Guevara, A. De: Epístolas Familiares, Biblioteca de Autores Españoles, Madrid, 1850, pag 215.

82. Obras de Cervantes, Baudry, 1851, p. 80.

83. SaAVEDRA FAJARDO, D.: Idea de un príncipe político-cristiano, Madrid, 1819, p. 196.

84. EGIDO, T.: Sátiras políticas de la España moderna, Madrid, 1973, p. 94.

85. Obras escogidas, Madrid, 1788, El entremetido, la Dueña y el Soplón, p. 502.

86. MARIANA, Juan de: Discurso de las enfermedades de la Compañia, BAE, Madrid, 1768, p. 113.

87. SANTAMARÍA, Juan de: Tratado de república y policía cristiana para reyes y príncipes y para los que en el gobierno tienen sus veces, Barcelona, 1618, p. 195.

88. MarianA, Juan de: Historia de España, BAE, Madrid, 1854, vol 2, p. 199.

89. Gracián, B.: Agudeza y arte de ingenio, Amberes, 1702, p. 310. 
se presentaba al fin como uno de los grandes caminos de la virtud. Para Lutero la música constituía el mayor regalo de $\operatorname{Dios}^{90}$. Las primeras enseñanzas del cristianismo ya hablaban de la naturaleza como regalo o don del plan de Dios, que el ser humano debía esforzarse en cuidar con esmero ${ }^{91}$. Moro en su carta de 1505 escrita a Joyeuce Leigh se expresaba en este sentido: «Por consiguiente, querida hermana mía, como prenda de este año nuevo que empieza te envío este regalo, para que sea testigo de mi tierno afecto,. (...) Y si los regalos de otras gentes declaran que lo que desean a sus amistades es la buena fortuna temporal, el mio es testigo de que te deseo la prosperidad espiritual $\rangle^{92}$. Por algo recibir letras de un ser querido se entendía en sí mismo en términos de regalo espiritual: «Lo que os pido, por amor de Dios, es que no dejéis de escribirme, pues sabéis que no tengo en esta vida cosa de mayor regalo.... ${ }^{93}$.

La cruzada moral contra el regalo ostentoso tiene también su razón de ser por la dimensión persuasiva de éste, por sus logros intencionados, a veces alejados de la razón cuyo recto camino no necesita acompañarse de alardes tales para triunfar ${ }^{94}$. La literatura de la época muestra esta otra versión del regalo, como acto de persuasión. En Los cabellos de Absalón, de Calderón, el protagonista no duda en confirmar sus intenciones cuando dice «Antes el gusto y regalo que he de hacerle ha de abonarme en esto pienso esmerarme $\rangle^{95}$. De similar modo lo hace el mismo autor en Mañanas de abril y mayo: «... dadme vuestra casa adonde pueda vella; tapada vendrá a ella. Yo he menestre a Arceo que se venga conmigo, que deseo, mientras llega, advertido, tener algun regalo prevenido...» ${ }^{96}$. Muchas de las comedias calderonianas que derivan en tragicomedias utilizan precisamente el regalo, regalo «envenenado», como núcleo dramático que alberga malentendidos, esperanzas frustradas y traiciones.

En éste sentido el regalo materializa una desviación intencionada del orden establecido familiar, por cuanto es secreto y se urde como estrategia para alcanzar lo que por medios más visibles no se podría obtener, como corruptor, en fin, de la vida cotidiana familiar. Los regalos entregados secretamente a una amada fuera del alcance de conocimiento de sus padres o contra el parecer de ellos, plantean una alternativa a la construcción del matrimonio basada en la obediencia. En el entremés de Quevedo titulado Diego Moreno, la dueña Gutiérrez se presenta como consejera de doña Justa y organizadora de sus amores adúlteros: «Hija, ya que estamos solas, oye una lición. $Y$ es que tú no has de desechar ripio. De cada uno toma lo que te diere, así del carnicero carne, como del especiero especias, del confitero dulces, del mercader vestidos, del

90. Bombi, A.; CARreras, M.A. (eds.): Música y cultura urbana en la edad moderna, Valencia, 2005, p. 351.

91. FERNÁNDEZ, S.: Figuras españolas del renacimiento y el barroco, México, 1996.

92. SilvA, A. de: un hombre para todas las horas. La correspondencia de Tomás Moro, Madrid, 1998, p. 45.

93. SAeZ, C.; CAStillo GomeZ, A.: La correspondencia en la historia. Modelos y prácticas de literatura epistolar, Madrid, 2000, p. 104. Carta de Francisca de Jesús a su hijo Francisco Torquemada, en 1632.

94. SCOTT, A.: Selfish gifts: the politics of exchange and English courtly literature, Cranbury, 2006.

95. Comedias de Calderón, BAE, Madrid, 1862, p. 430.

96. Comedias de D. Pedro Calderón, tomo I, Leipsique, 1827, p. 642. 
sastre hechuras, del zapatero servillas, del señor joyas, del ginovés dineros, del letrado regalos, del médico curas, del alguacil amparo, del caballero oro, del hidalgo plata y del oficial cascajo. Sólo has de huir de valientes que te regalarán con estocadas y te darán en votos y juros lo que no has menester en censos; de apartarte de los músicos, porque ya no se come con pasos de garganta, sino con qué tener que pasar por ella. ¿Pues poetas? Gente apestada: con un soneto te harán pago si los quieres y con una sátira si los dejas» ${ }^{97}$. Como es bien sabido, el estilo celestinesco ya muestra al galán obsequiando con regalos a su amada, para al fin persuadirla y conquistarla contra las intenciones de la familia. En semejantes aventuras el regalo une a señores y a criados, que comparten el secreto de los primeros y se convierten en portadores de los objetos intercambiados. También en ése ambiente, escribe Teijeiro, son protagonistas los regalos cómplices, aquellos que van a mejorar la situación económica de los criados al convertirse estos en propiciadores de encuentros amorosos entre la pareja ${ }^{98}$. Según un relato testifical que recoge López Vela, un inquisidor de Málaga del siglo XVII, de nombre Ozores, «dedicaba grandes esfuerzos y hacía grandes dispendios para lograr sus conquistas entre mujeres generalmente casadas a las que hacía valiosos regalos $\gg{ }^{99}$. Las comedias del Barroco narran episodios en los que el regalo constituye, pues, un instrumento de consecución que debiera provocar desconfianza. Veamos otros ejemplos. Los personajes lopescos son conocedores de los engaños y traiciones a que pueden conducir los regalos, pues «Cualquier artificio es malo y yo lo tengo por regalo» ${ }^{100}$. Aprenden a no fiarse de sus apariencias y a mal pensar de su ofrecimiento: «Ay Leonor, es forastero, y no hay forastero malo, porque en efecto se va y así lo poco que da, se tiene por mas regalo» ${ }^{101}$. Sin duda serían muchos más los textos en los que el acto de regalar sigue al devenir mismo de la vida cotidiana, sus construcciones y sus rupturas.

\section{ALGUNAS CONCLUSIONES}

El acto de regalar va más allá del mero dar y recibir: encierra o manifiesta aspiraciones y cambios. Como ya se ha demostrado en varias ocasiones, el estudio de las prácticas del regalo ofrece nuevas y variadas perspectivas de las relaciones sociales, de lo individual en función de sus nexos e intereses con el conjunto circundante, pero también de la vinculación entre las personas y los objetos, entre las personas y los valores que éstas atribuyen muy particularmente a los tiempos y los espacios y todo ello tiene una dimensión histórica. Al margen de esto, a lo largo de las páginas que

97. Borrego, E.: «De dueñas, celestinas y entremeses», Enlaces, 2003, p. 3.

98. TeiJeIro Fuentes, M.: «El 'planteamiento' en el teatro renacentista: del modelo celestinesco a la propuesta naharresca», Revista sobre teatro áureo, 1, 2007, p. 195.

99. Lopez Vela, R.: «La sexualidad del inquisidor Ozores...», FORTEA, J.I.; GELABERT, J.E.; MANTECÓN, T, (eds.), Furor et rabies. Violencia, conflicto y marginación en la edad moderna, Santander, 2002, p. 498.

100. Lope DE VeGA: Comedias, II parte, Bruselas, 1611, El mayorazgo dudoso, p. 188.

101. LoPE DE VEGA: El acero de Madrid, Madrid, ed. de 1836, p. 35. 
preceden hemos intentado situar en lo cotidiano el flujo de ideas que existen detrás de las prácticas del regalo, y las observan y juzgan como acto político y moral. El regalo, en la edad moderna y en todos los tiempos, no es sólo expresión de vínculo en las relaciones humanas, una celebración de amistad, convivencia o festividad; el regalo, pensado y entregado, también potencia o resquebraja un determinado orden. Es un elemento que se enmarca en la cotidianeidad, que usa con eficacia de sus espacios y sus tiempos, pero que a la vez es capaz de truncar la cotidianeidad deseada. Y precisamente contra esto último unen sus esfuerzos todos los tratadistas morales y políticos, también los autores de comedias y obras de teatro, que meditan sobre las relaciones humanas. De sus textos se observa con nitidez el abanico de usos y percepciones del regalo, del regalo dañino al virtuoso, abanico que enlaza con el sempiterno debate de la búsqueda de la virtud y la lejanía del engaño que preside la educación de la época. El regalo se desvela pues como acto político y moral: como elocución del gobierno de sí mismo, de lo que ha de seguir la reproducción social y cultural; como parte del gobierno de la comunidad, en su dimensión primaria, esto es, en el espacio de las familias o de las relaciones entre hombres y mujeres. Acto político y moral, en definitiva, que constituye tanto en la dimensión práctica como teórica, una de las constantes vertebradoras de la vida cotidiana. 